\title{
A Study of Temperature Effect on the Rayleigh Velocity of Superconductor Material Type Bi2212 Using Acoustic Techniques
}

\author{
N. Sayoud, S. Chouf, and A. Boudour \\ Badji Mokhtar University, \\ B.P. 12 \\ CP 23000 Annaba, Algeria
}

In the present work, the effect of the temperature on Rayleigh velocity $V_{R}$ of superconductor material type Bi2212 is studied, focusing on the modelling of both the reflection coefficient $R(\theta)$ and the acoustic signature $V(z)$. Consequently, the study allows us to deduct the velocities of the acoustic waves of surface and volume, following their evolution as functions of temperature. The study is carried out in case of porous and non-porous superconductor material type $\mathrm{Bi} 2212$ in a temperature range from 10 to $295 \mathrm{~K}$ and with work frequency of $600 \mathrm{MHz}$. This modelling study is based on experimental results obtained on porous and non-porous Bi2212 superconducting materials in the temperature range of 10 to $295 \mathrm{~K}$ at a frequency of $600 \mathrm{MHz}$.

Key words: Rayleigh velocity, reflection coefficient, acoustic signature, superconductor type Bi2212, porosity.

У даній роботі досліджено вплив температури на Релейову швидкість $V_{R}$ надпровідного матеріялу типу $\mathrm{Bi} 2212$, зосереджуючись на моделюванні коефіцієнта відбиття $R(\theta)$ та акустичної характеристики $V(z)$. Дослідження уможливлює вирахувати швидкості поверхневої й об'ємної акустичних хвиль за їхньою еволюцією, залежно від температури. Дослідження проводилося для випадку пористого та непористого надпровідникового матеріялу типу Вi2212 за температури від 10 до $295 \mathrm{~K}$ та робочої частоти у 600 МГц. Таке моделювання базувалося на експериментальних результатах, одержаних на пористих і непористих надпровідних матеріялах

Corresponding author: Amar Boudour

E-mail: amiredyoune@gmail.com

Citation: N. Sayoud, S. Chouf, and A. Boudour, A Study of Temperature Effect on the Rayleigh Velocity of Superconductor Material Type Bi2212 Using Acoustic Techniques, Metallofiz. Noveishie Tekhnol., 40, No. 9: 1173-1184 (2018), DOI: $10.15407 /$ mfint.40.09.1173. 
Вi2212 в діяпазоні температур від 10 до 295 К за частоти у 600 МГц.

Ключові слова: Релейова швидкість, коефіцієнт відбиття, акустична характеристика, надпровідник типу Вi2212, пористість.

В данной работе изучалось влияние температуры на скорость Рэлея $V_{R}$ сверхпроводникового материала типа Вi2212, сосредоточиваясь на моделировании коэффициента отражения $R(\theta)$ и акустической характеристики $V(z)$. Исследование позволяет рассчитать скорости поверхностной и объёмной акустических волн, следуя их эволюции в зависимости от температуры. Исследование проводилось для случая пористого и непористого сверхпроводника типа Вi2212 при температуре от 10 до $295 \mathrm{~K}$ и рабочей частоте 600 МГц. Такое моделирование основано на экспериментальных результатах, полученных на пористых и непористых сверхпроводящих материалах $\mathrm{Bi} 2212$ в диапазоне температур от 10 до $295 \mathrm{~K}$ на частоте 600 МГц.

Ключевые слова: скорость Рэлея, коэффициент отражения, акустическая характеристика, сверхпроводник типа Вi2212, пористость.

(Received December 28, 2017)

\section{INTRODUCTION}

The non-destructive control technique (NDT) was strongly contributed in characterizing and best understanding of several materials [1, 2]. The scanning acoustic microscopy developed by Quate et al. [3, 4] is the one among the non-destructive characterization techniques widely used for determining both the elastic proprieties of a material and their different propagation speed such as longitudinal $\left(V_{L}\right)$, transversal $\left(V_{T}\right)$, and Rayleigh velocities $\left(V_{R}\right)$. Since this technique has been used for characterizing various superconductor compounds [5-10], therefore, our study was devoted to carry out the modelling of the acoustic signature $V(z)$ and the reflection coefficient $R(\theta)$, in case of porous and non-porous superconductor compound type Bi2212, in order to determine the evolution of the velocity of wave surfaces (Rayleigh velocity) as a function of temperature.

\section{THEORY}

\subsection{Coefficient of Reflection}

The determination method of the coefficient $R(\theta)$ expression by using the mechanical balance, the continuity of constraints and the displacement to the interface has been developed by Brekhovskikh [11]. The reflection coefficient for a massive material is given by the following expression [12]: 


$$
R(\theta)=\frac{Z_{L} V_{L} \cos ^{2} 2 \theta_{L}+\rho_{T} V_{T} \sin ^{2} 2 \theta_{T}-Z_{l i q}}{Z_{L} V_{L} \cos ^{2} 2 \theta_{L}+\rho_{T} V_{T} \sin ^{2} 2 \theta_{T}+Z_{l i q}}
$$

where $Z_{l i q}$ is the acoustic impedance of liquid, $Z_{L}$ and $Z_{T}$ are the longitudinal and transverse acoustic impedances of solid, respectively.

The total impedance in a solid is given by the following equation:

$$
Z_{\text {Tot }}=Z_{L} \cos ^{2} 2 \theta_{L}+Z_{T} \sin ^{2} 2 \theta_{T}
$$

but

$$
R(\theta)=\frac{\rho_{L} V_{L}}{\cos \theta_{L}} \cos ^{2} 2 \theta_{L}+\frac{\rho_{T} V_{T}}{\cos \theta_{T}} \sin ^{2} 2 \theta_{T} .
$$

We get the relation of the well-known reflection coefficient in acoustics as follows:

$$
R(\theta)=\frac{Z_{\text {Tot }}-Z_{l i q}}{Z_{\text {Tot }}+Z_{l i q}} .
$$

In the general case and under any impact, the angles of refraction $\theta_{L}$ and $\theta_{T}$, and subsequent the acoustic impedances $Z_{L}$ and $Z_{T}$ are complex numbers. The reflection function may be expressed, therefore, following the complex form [12]:

$$
R(\theta)=\Gamma \exp (j \xi),
$$

where $\Gamma$ is the module of $R(\theta)$ and $\xi$ is its phase (Figs. 2-4).

\subsection{Acoustic Signature}

By definition, the variation of the signal tension of exit $V$ as a function of the distance ' $z$ ', separating the focal point of the lens and the surface of the sample are known under the name of acoustic signature $V(z)$ that plays an important role in the image constraints. The curve of acoustic signature may be experimentally obtained by recording the variation of the signal amplitude in a function of vertical displacement $z$ of the lens to the sample [12].

The expression of the acoustic signature is given by the following relation [13]:

$$
V(z)=\int_{0}^{\theta_{\max }} P^{2}(\theta) R(\theta) \exp \left(2 j k_{0} z \cos \theta\right) \sin \theta \cos \theta d \theta,
$$

where $k_{0}$-number of wave in the coupling liquid, $z$-defocusing of the 
sensor with respect to the focal length, $R(\theta)$-ability of material reflector, $P(\theta)$-pupil function of the lens.

The different models of the acoustic signature calculation require the knowledge of reflector ability of structures as a function of wave incidence. The model widely used is that of Sheppard and Wilson [14]. The period $\Delta z$ of the acoustic signature $V(z)$ may be determined according to the signal treatment techniques, such as the fast Fourier transform (FFT), which is known as a spectral method used in signal treatments.

On the other hand, the acoustic signature $V(z)$ formed of the pseudoperiodic signals (Figs. 8, 9 and 10), and the periodicity $\Delta z$ of the interferences provide the information about the acoustic wave of surface, and subsequently, it may be calculated according to the following relation [12]:

$$
\Delta z=\frac{V_{l i q}}{2\left(1-\cos \theta_{R}\right)},
$$

where $V_{R}$-velocity of coupling liquid, $\theta_{R}$-Rayleigh's critical angle.

Thus, we can deduct the velocity of surface wave propagation (or velocity of Rayleigh), using the following relation [12]:

$$
V_{R}=V_{l i q}\left[1-\left(1-\frac{V_{l i q}}{2 f \Delta z}\right)^{2}\right]^{-1 / 2},
$$

where $f$-frequency of work of the acoustic microscope.

\section{RESULTS AND DISCUSSION}

In this work, we studied the evolution of Rayleigh velocity as a function of temperature ranging from 10 to $295 \mathrm{~K}$, and in case of porous and non-porous superconductor material type Bi2212, along with porosity rate of 0.32 and 0.50 . Herein, we established the relationship between the Rayleigh velocity $V_{R}$ and the temperature $T$ for a constant work frequency equals to $600 \mathrm{MHz}$. Since our study is a modelling, we focused on the experimental results obtained by Chang Fanggao et al. [15]. Their results gave the variation of the longitudinal and the transversal velocities as a function of temperature for the studied superconductor material.

Figure 1 shows the evolution of different mode velocities that propagate in the superconductor material type $\mathrm{Bi} 2212$ (case of porosity rate of 0.32 ) as a function of temperature.

We can notice that the transversal and longitudinal velocities [15] decrease when temperature increases. Since the surface mode (Ray- 
leigh) is related to the different modes of propagation of longitudinal and transversal waves, the decrease in these velocities as a function of temperature would directly affect the mode surface. This promotes us to develop a program, leading to obtain the reflection coefficient $R(\theta)$ (module and phase) and the acoustic signature $V(z)$ of the studied material. In the present work, we have used the methanol as a coupling liquid to avoid the recovery of modes type Bi2212, counter to water, along with a work frequency of $600 \mathrm{MHz}$.

As shown in Figs. 2, 3 and 4, the modelling of reflection coefficient $R(\theta)$, (amplitude $(a)$ and phase $(b)$ ) allow us to deduce the angles of dif-

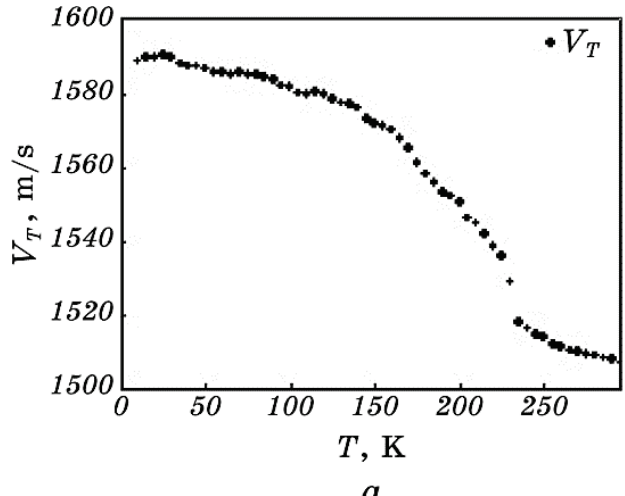

$a$

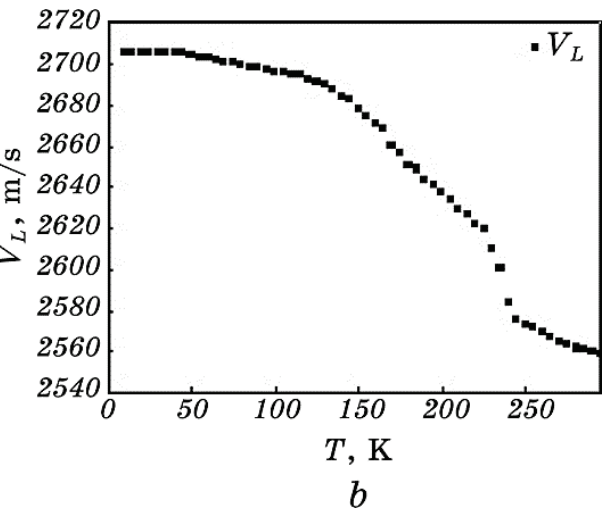

Fig. 1. Evolution of transversal and longitudinal velocities of Bi2212 as a function of temperature [15].

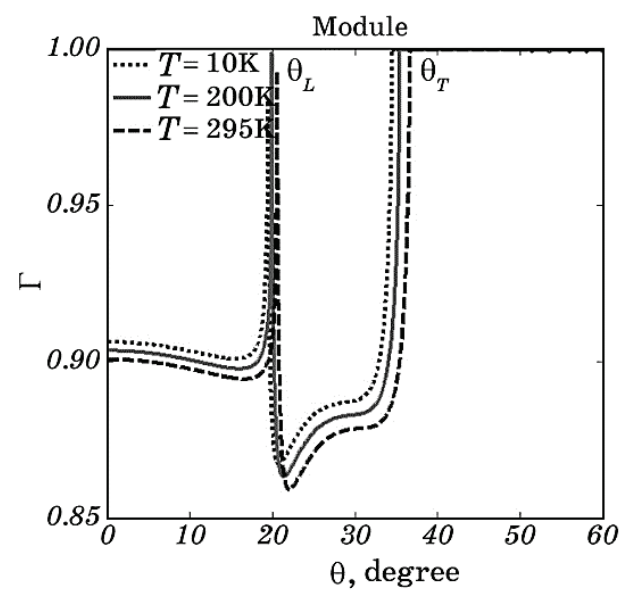

$a$

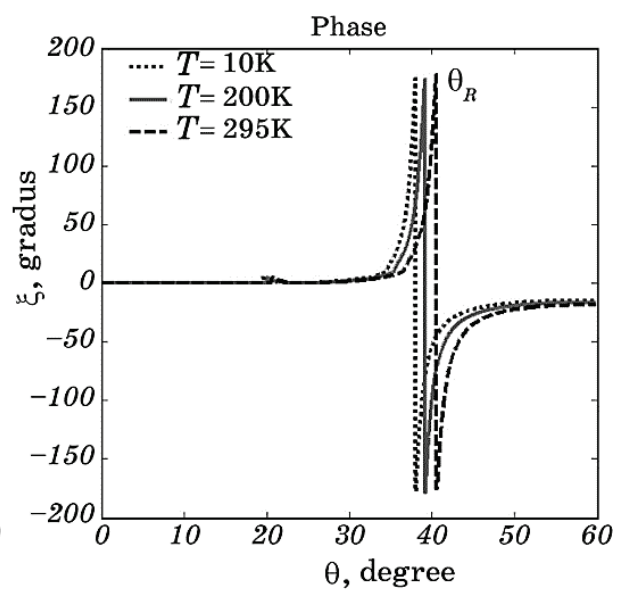

$b$

Fig. 2. Variation of the reflection coefficient $R(\theta)$ as a function of temperature of $\operatorname{Bi2212}(p=0)$. 
ferent mode propagations of longitudinal, transversal and Rayleigh waves for the three temperatures and the porosity of $0.32,0.5$ and 0 .

The values of the critical angles of different longitudinal $\left(\theta_{L}\right)$ and transversal $\left(\theta_{T}\right)$ modes are determined from the module of reflection coefficient $R(\theta)$, whilst the critical angle of Rayleigh $\theta_{R}$ is obtained from the phase $R(\theta)$, using the Snell-Descartes rule:

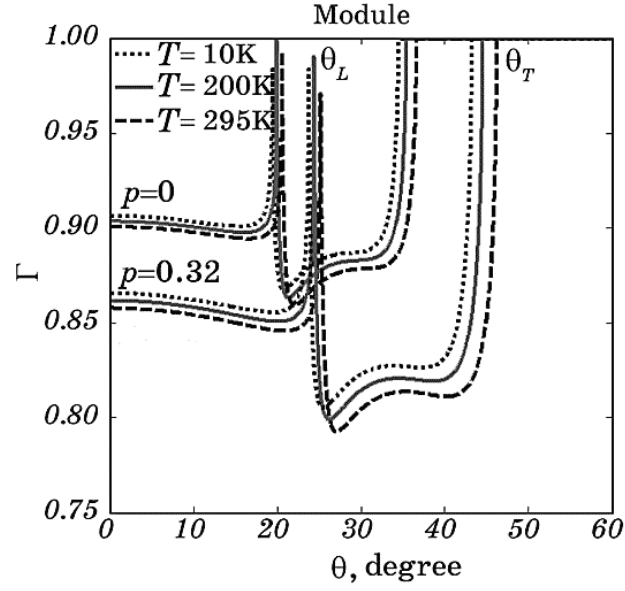

$a$



$b$

Fig. 3. Variation of the reflection coefficient $R(\theta)$ as a function of temperature of $\operatorname{Bi} 2212(p=0$ and $p=0.32)$.

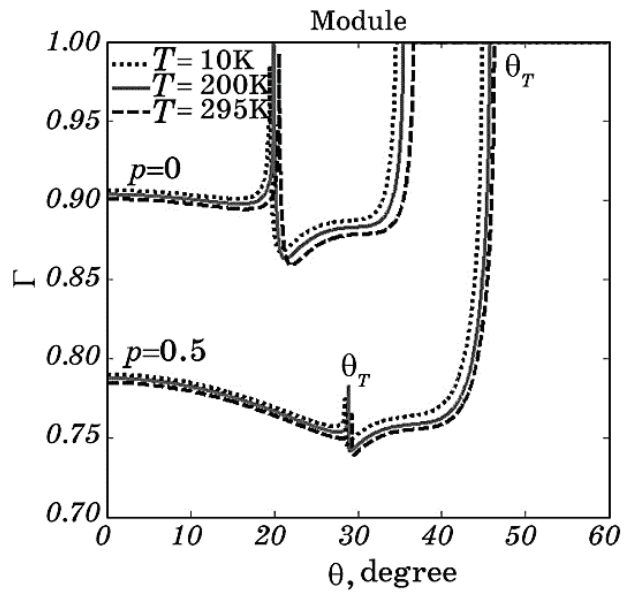

$a$

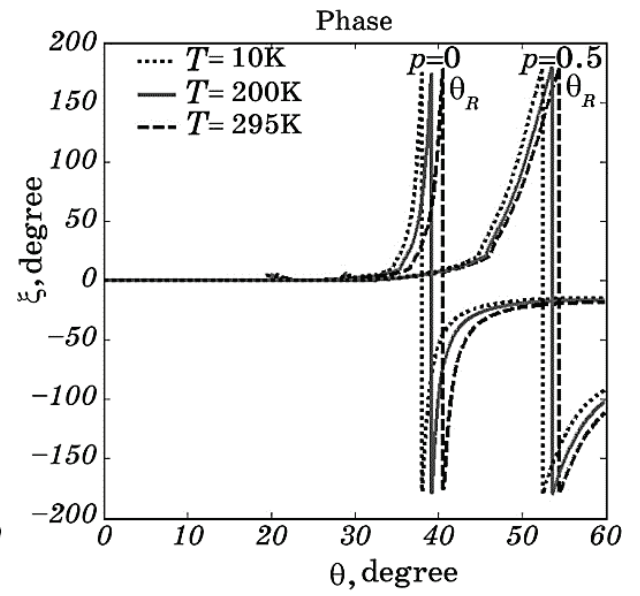

$b$

Fig. 4. Variation of the reflection coefficient $R(\theta)$ as a function of temperature of $\operatorname{Bi} 2212(p=0$ and $p=0.5)$. 


$$
V_{R}=\frac{V_{l i q}}{\sin \theta_{R}}, \quad V_{T}=\frac{V_{l i q}}{\sin \theta_{T}}, \quad V_{R}=\frac{V_{l i q}}{\sin \theta_{L}} .
$$

Since the coupling liquid velocity (methanol) equals $108 \mathrm{~m} / \mathrm{s}$, we note that the increased temperature leads to the displacement of critical angles: $\theta_{L}, \theta_{T}$ and $\theta_{R}$ reach to the higher angles. This is due to the de-

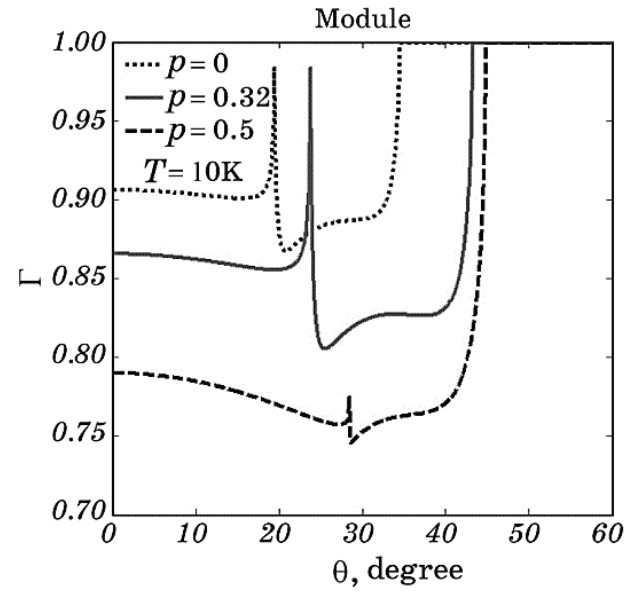

$a$

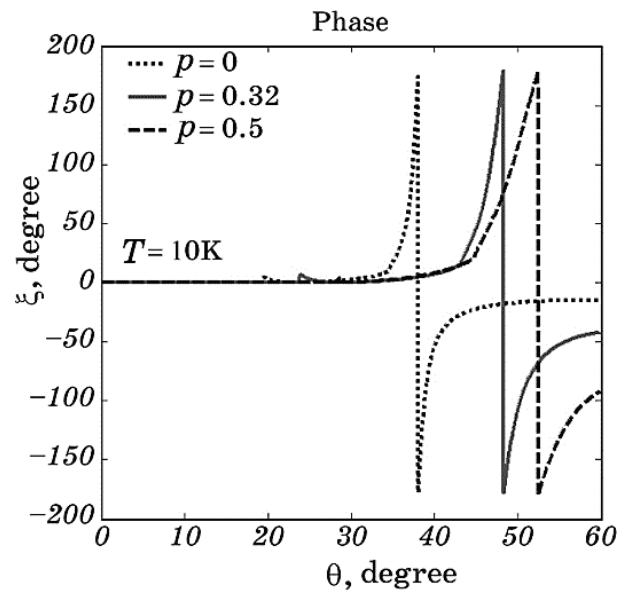

$b$

Fig. 5. Variation of reflection coefficient $R(\theta)$ as a function of the porosity $\operatorname{Bi} 2212(T=10 \mathrm{~K})$.



$a$

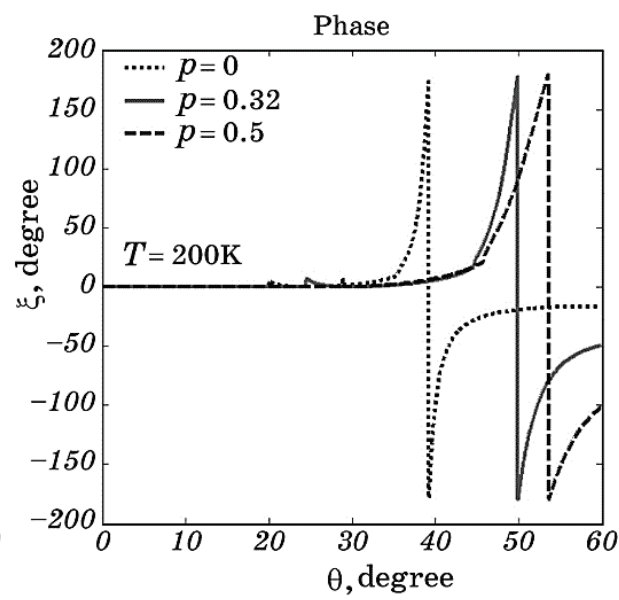

$b$

Fig. 6. Variation of reflection coefficient $R(\theta)$ as a function of the porosity $\operatorname{Bi} 2212(T=200 \mathrm{~K})$. 
crease in velocity of these modes, and thus, we note the same evolution, when we vary the porosity rate (Figs. 5-7).

From the reflection coefficient $R(\theta)$, we have deducted the acoustic signature $V(z)$ for various porosity rates $(0.32,0.5$ and 0$)$ following various temperature values (Fig. 8).

The acoustic signature treatment $V(z)$ by the FFT and the application of the Blackman window at $92 \mathrm{~dB}$, allow us to determine the Ray-

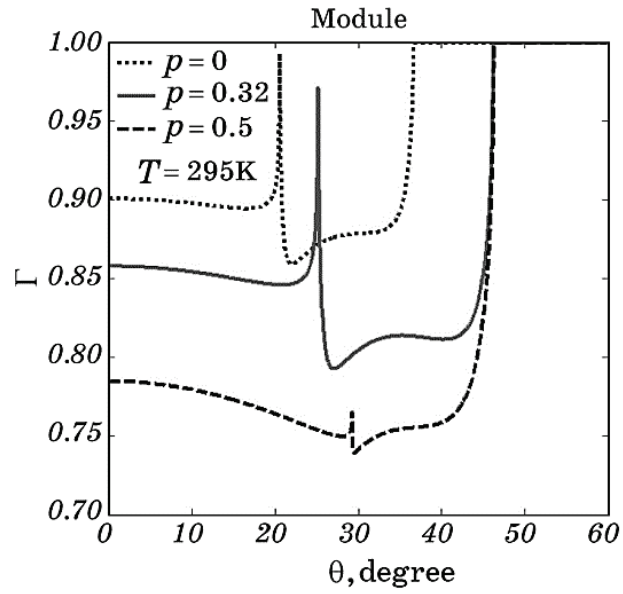

$a$

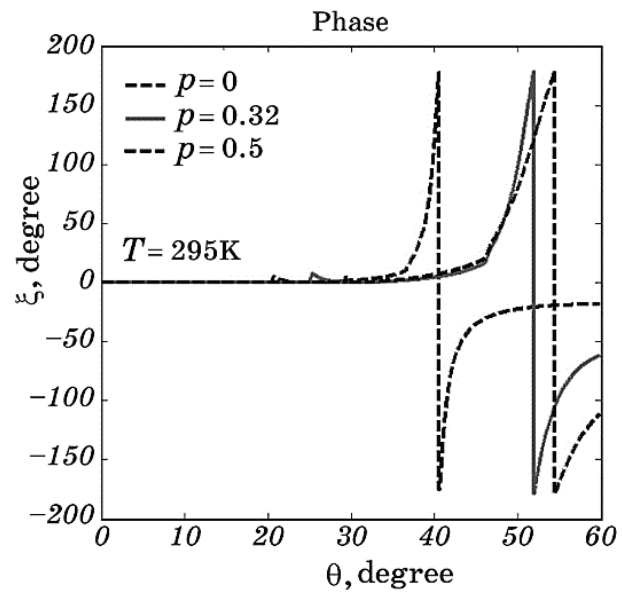

$b$

Fig. 7. Variation of reflection coefficient $R(\theta)$ as a function of the porosity $\operatorname{Bi} 2212(T=295 \mathrm{~K})$.

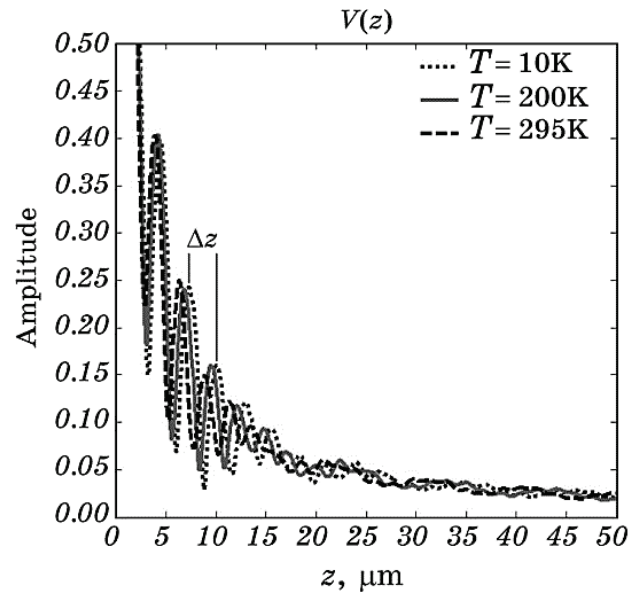

$a$

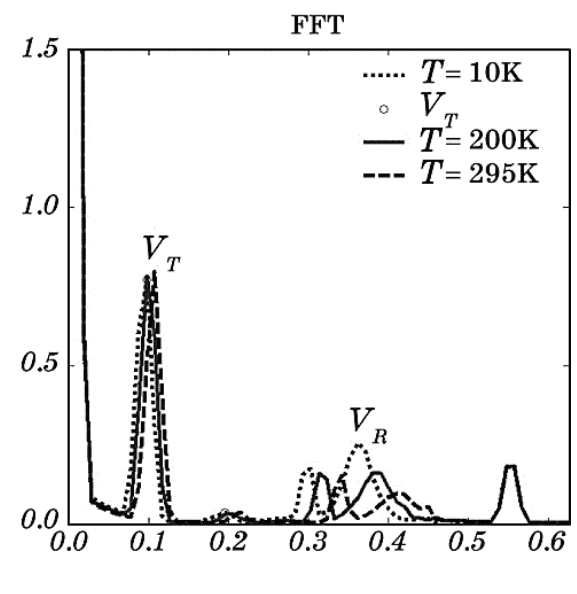

$b$

Fig. 8. Acoustic signature $V(z)$ and its FFT as a function of temperature of $\operatorname{Bi} 2212(p=0.32)$. 
leigh velocity. These parameters are grouped in Figs. 9 and 10, showing the different acoustic signature $V(z)$ as a function of the porosity.

As seen in Fig. 9, the increased porosity leads to signal attenuation, engendering a decrease in the Rayleigh velocity. For a fixed porosity

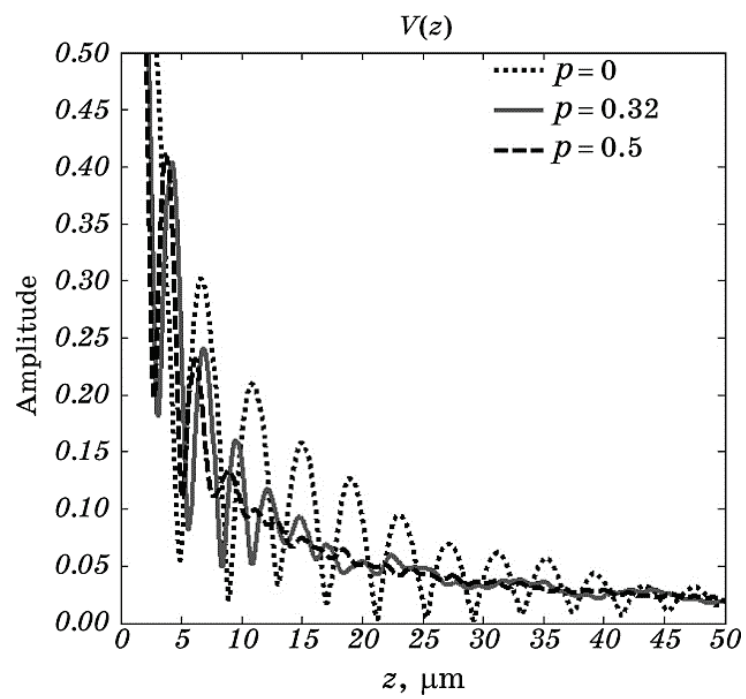

Fig. 9. Acoustic signature $V(z)$ of Bi2212 for different values of porosity at $200 \mathrm{~K}$.

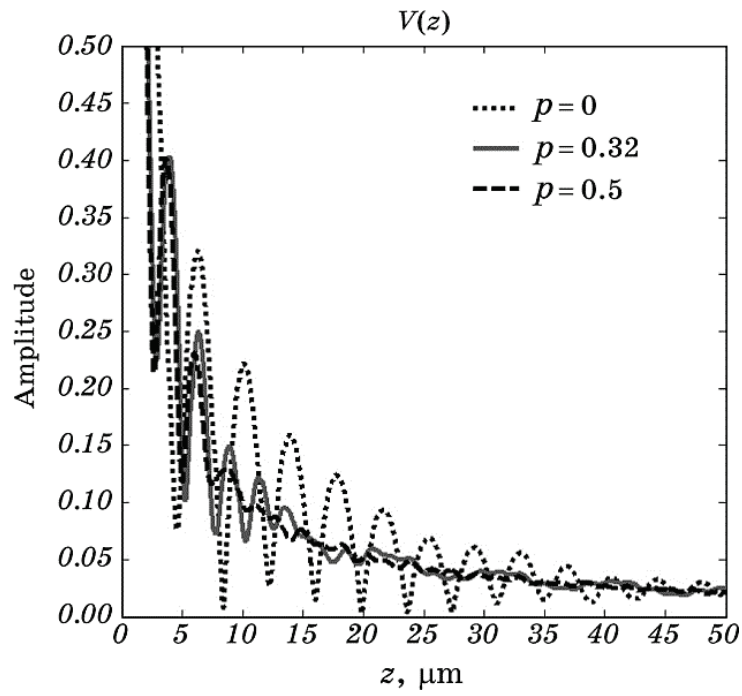

Fig. 10. Acoustic signature $V(z)$ of $\mathrm{Bi} 2212$ for different values of porosity at $295 \mathrm{~K}$. 
rate, this velocity decreases with the temperature (Fig. 11). Hence, Figure 11 shows the effect of the porosity and the temperature on the Rayleigh velocity. In addition, we notice that, if the temperature increases, the Rayleigh velocity decreases for the three considered porosities.

Taking the importance of the effect of temperature on the Rayleigh velocity leads to establish the relationship as a function of these curves. We obtained the relation (10) following a polynomial form of order 5:

$$
V_{R}=B_{0}+B_{1} T-B_{2} T^{2}+B_{3} T^{3}-B_{4} T^{4}+B_{5} T^{5},
$$

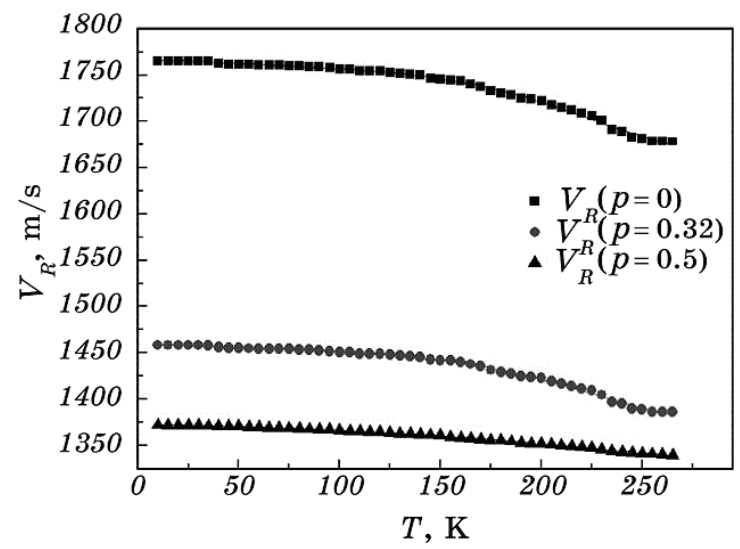

Fig. 11. Dispersion of Rayleigh velocity as a function of temperature for different porosity rates.

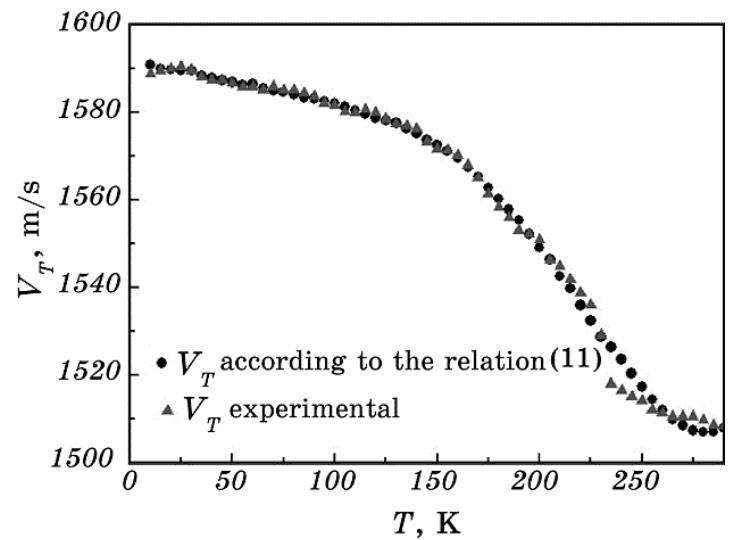

Fig. 12. Comparison between the experimental transversal velocity and those determined according to the relation (11). 
where $B_{0}, B_{1}, B_{2}, B_{3}, B_{4}$ and $B_{5}$ are polynomial parameters.

To check the relation (10), we needed to determine the transversal velocity as described elsewhere [12]. Here, we can establish the relation between the Rayleigh and the transversal velocities:

$$
V_{T}=V_{R}\left(1.14418-0.25771 \sigma+0.12661 \sigma^{2}\right) .
$$

The determined velocity from the relation (11) as a function of temperature is alike to those obtained in the experimental measures (Fig. 12) [15]. We noticed also the decrease in the transversal velocity as a function of temperature, as well as the obtained results from the relation (11) is indicated to the experimental results.

\section{CONCLUSION}

In the present work, we have described a new approach to characterize the materials using the concept of the acoustic microscope. We have established the relationship between the Rayleigh velocity and the temperature, using the acoustic signature $V(z)$ and the reflection coefficient $R(\theta)$ for various porosity rates of a superconductor material type Bi2212. This study may be generalized in the characterization of different superconductor materials, focusing on the established relationship, leading to determine the different elastic parameters $E, G$, and $v$.

\section{REFERENCE}

1. Z. Yu and S. Boseck, Rev. Mod. Phys., 67, Iss. 4: 863 (1995).

2. S. Debboub, Y. Boumaïza, A. Boudour, and T. Tahraoui, Chin. Phys. Lett., 29, No. 4: 044301 (2012).

3. C. F. Quate, A. Atalar, and H. K. Wickramasinghe, Proc. IEEE, 67, Iss. 8: 1092 (1979).

4. R. A. Lemons and C. F. Quate, Proc. IEEE Ultrasonics Symp. (Sept. 26-28, 1979, New Orleans, LA, USA), p. 18.

5. N. A. Rasih and A. K. Yahya, J. Alloys Compd., 480, Iss. 2: 777 (2009).

6. W. Abdeen, A. El. Tahan, R. Awad, A. I. Abou Aly, E. M. El-Maghraby, and A. Khalaf, Appl. Phys. A, 122, Iss. 6: 574 (2016).

7. M. B. Solunke, K. B. Modi, V. K. Lakhani, K. B. Zankat, P. U. Sharma, P. V. Reddy, and S. S. Shah, Ind. J. Pure Appl. Phys., 45, No. 9: 764 (2007).

8. T. Tahraoui, Y. Boumaïza, and B. Boudour, Optoelectron.Adv. Mater., 4, No. 11: 1771 (2010).

9. R. Ravinder Reddy and P. Venugopal Reddy, Physica C, 265, Iss. 1-2: 96 (1996).

10. S. Ismail, A.-B. M. A. Ibrahim, and A. K. Yahya, Phase Transitions, 88, Iss. 7: $692(2015)$.

11. L. M. Brekhovskikh, and O. A. Godin, Acoustic of Layered Media I: Plane and 
Quasi-Plane Waves (Berlin: Springer-Verlag: 1990).

12. G. A. D. Briggs, Acoustic Microscopy (Oxford: Oxford University: 2010).

13. J. David and N. Cheeke, Fundamentals and Applications of Ultrasonic Waves (Montreal: Concordia University Montreal: 2002).

14. C. J. R. Sheppard and T. Wilson, J.Appl. Phys. Lett., 38, Iss. 11: 858 (1981).

15. Chang Fanggao, M. Cankurtaran, G. A. Sauders, D. P. Almond, P. J. Ford, and A. Al-Kheffaji, Supercond.Sci. Technol., 3, No. 11: 546 (1990). 